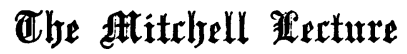

\author{
ox
}

\section{TUBERCULOSIS OF THE LARYNX:}

\author{
ITS SIGNIFICANCE TO THE PHYSICIAN.
}

\author{
Delivered before the Royal College of Physiciats of \\ LoNdox, November 6th, 1924, \\ BY \\ Sir StClair THOMSON, M.D.
}

It rould not be an exaggeration to say that to-dar, in England and Wales, there are 106,990 individuals afflicted with tuberculosis of the larynx. This figure is arrived at in the following manner: In the year 1923 the deaths from pulmonary tuberculosis amounted to 32,097.* Now, statisticians are of opinion that for every single case which succumbs during a year there are ten others still suffering from it; this gives us 320,970 as the number of consumptive invalids in one year. Of these 320,970 patients the proportion who must have a laryngeal complication is at least one in three; and so we arrive at 106,990 as a modest estimate of the number of those who, in this country to-day, require relief or cure for tuberculosis of the larynx.

Of every ten persons born one is going to die of tuberculosis, and, as a rule, he will succumb while in the prime of life. Tuberculosis is the most important disease with which humanity has to cope. There is no other specific disease so common in the larynx. As the 106,990 cases in this country to-day must look principally to the physician for guidance and help, it is well worth while considering what assistance in his task can be offered by a laryngologist who, during a period of ten years, has carefully watched the progress of 477 instances of Jaryngeal disease, in 2,541 patients with pulmonary tuberculosis. ${ }^{1}$

\section{Proportion of Laryngeal Cases in Pulmonary Tuberculosis.}

In the early years of this investigation one case out of every four had trouble in the larynx, while the average of the whole decade showed a proportion of 18.77 per cent. These patients were seen in a sanatorium and were relatively early cases, for the records of the post-mortem room show that the larynx is diseased in 48 to 83 per cent. of all fatal cases.

Suggestive Symptoms.-The physician would therefore be well advised to be prepared to encounter a laryngeal lesion in a considerable number of his consumptive patients. The importance of this recognition will be brought out later on. The two most suggestive symptoms to him will be - first, slight but persistent huskiness; and, secondly, discomfort referred to the throat, or even pain in swallowing. The latter is a symptom which is more frequent with advanced cases; therefore, for the all-important attainment of an early diagnosis, any hoarseness or any slight change in roice which does not clear up in two or three weeks should rouse suspicion and entail an expert examination of the larynx.

IVithout Change of Voice.-But we must not forget that tubercle occasionally invades the larynx without causing the slightest alteration of voice or any other local symptom. This is quite understandable if we remember that disease may be deposited in the epiglottis, on a ventricular band, or on the aryepiglottic fold without interfering with the glottis or impeding the clear vibration of the vocal cords. Of the 477 cases of laryngeal tuberculosis, I found no less than 57 ( 34 men and 23 women) who had no complaint of their throat, and whose voices-both to their own ear and to mine-sounded quite clear and normal. The regular physician should therefore be prepared for the possibility of a laryngeal lesion with his consumptive patients, even when they have a clear voice. The proportion is small;

* On the State of the Public Health. Annual Report of the Chief Medical officer of the Ministry of Health for the year 1923. His Majesty' Stationery Office, London. 1924. Price 3s. my 57 cases occurred in 2,541 patients-an average of only 2.2 per cent.; still, an examination of a patient with pulmonary tuberculosis-or even suspected of it-cannot be regarded as complete without a laryngeal inspection.

Proportion of Laryngal Cases in Relation to Sex.

Since the days when changes could be diagnosed in the larynx by the aid of the laryngoscope (invented by Manuel Garcia in $1854^{2}$ ) it has been accepted that men are more prone to develop laryngeal tuberculosis than women, just as the male larynx is regarded as more disposed than the female to be attacked with any disease. It used even to be thought that the female sex was less subject than the male to contract pulmonary tuberculosis. But it has been shown that any difference between the sexes in this respect is not, as regards tubercle, due to any sexual predisposition, but simply to the fact that, until recent times, women have led a more sheltered life and have been less exposed both to fatigue and to infection than men who work in office or factory. When both sexes are exposed to the same conditions, woman is just as subject to tuberculosis (in lungs or in larynx) as man-perhaps more so. A glance at Fig. 1 will show that the difference of laryngeal disease in the two sexes is so slight that it may be disregarded. The conclusion is that, amongst bread-winners, we must be prepared to find tubercle just as frequently in the larynx of the female as of

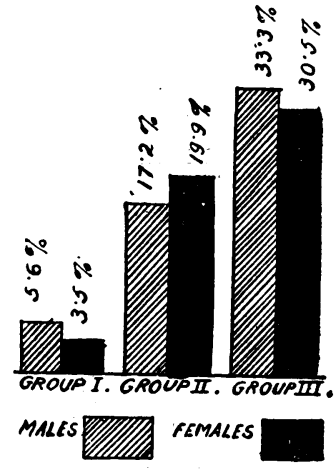

Fuf. 1.- Percentage incidence of laryngeal cases in the two
sexes and in the three stages of julmonary tuberculosis. the male. Another conclusion is that man's greater indulgence in alcohol and tobacco does not seem to render his larynx more vulnerable to tuberculosis.

\section{Proportion of Laryngeal Cases in Relation to Stage of Pulmonary Disease.}

It has long been established that the frequency with which the larynx is invaded increases with the progress of the pulmonary disease. This may occur even in $4.8 \mathrm{per}$ cent. of cases in an early stage of the disease. These are cases with limited lesions, and, at this period, might well be called "favourable." In severe cases the proportion mounts up to 18.3 per cent.; while in the advanced type of disease, which forms Group III of the Turban-Gerhardt classification, the proportion of laryngeal disease is almost double-namely, 31.5 per cent.

An inspection of the diagram (Fig. 1) shows that both women and men are increasingly liable to a laryngeal lesion with the progress of the pulmonary disease. - Only one out of every twenty poitrinaires with an early.ilesion is liable to throat trouble; in more serious cases (that is, those in Group II of the Turban-Gerhardt classification) the proportion may be one in five; and in the advanced cases of Group III one patient in every three will have the disease in the larynx. This development-as will be shown laterdiminishes so markedly the prospect of recovery that it emphasizes the great importance of diagnosing pulmonary tubercle in its early stage and persuading the patient to submit to the best treatment.

\section{Region of Larynx Attaclicd.}

Tubercle may deposit in any part of the larynx, but it may help towards an early diagnosis of more cases if a keen look-out is kept on the region most commonly attacked. It is quite certain that the favourite site is the neighbourhood of the posterior commissure-that is, the interarytenoid area, the anterior surface of the arytenoid bodies, and the vocal processes (Fig. 2). The vocal cords come next in frequency," while the epiglottis and the region of the anterior commissure are attacked more rarely and are generally late extensions of the disease. Now, the importance of bearing this fact in mind is that it is just around the margin of the posterior commissure that the disease 
is most curable, and yet it is an area which is frequently overlooked. Reports are very commonly sent up with the remark that "the arytenoids are swollen," or that " the

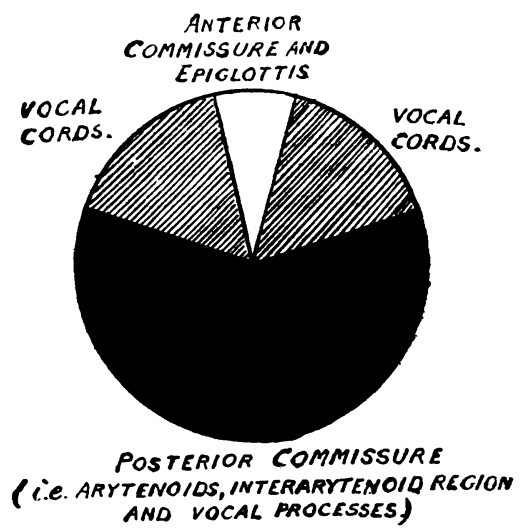

Fig. 2-Distribution of lesions in different regions of the larsnx.

cords are not ulcerated." But the latter is not the most common lesion, and by the time that an arytenoid is swollen the disease is advanced and generally hopeless.

Prognosis of 'Tuberculosis iv the Laryxx.

To forecast the possible course of a lesion in the larynx requires the careful balancing of a large number of factors, general and local, and hardly comes within the scope of this lecture. What the prospect is of a local cure may be estimated by a study of the accompanying table (p. 843), which shows the results of treatment in nearly 500 cases of the disease. Of much more importance to the general physician is an appreciation of what tuberculosis in the larynx counts for in regard to the mortality of pulmonary cases.

\section{The Prognostic Value of Tuberculesis of the Larynx in} regard to Mortality.

In treatises on medicine or on pulmonary tuberculosis it is not unusual to read that, if the disease attacks the larynx, it "adds distressing features to the case," or "increases the gravity of the outlook." These statements I. entirely endorse, but I hardly think it is generally realized that this complication is such a serious one-only less in gravity than a secondary invasion of the meningesand $I$ hope that the following observations may help to strengthen the position of the physician by encouraging him to work for an early diagnosis and to insist on prompt and suitable treatment.

Of the 2,541 patients with pulmonary tuberculosis who were discharged from the King Edward VII Sanatorium, Midhurst, between 1911 and 1921, the proportion of those alive between one and ten rear's later was, amongst those with a sound larynx, double that of those with tuberculous laryngitis. Of patients found to have tubercle in the larrnx during these ten years, two out of every three were dead. Of those with a sound larynx, it is the reverse -two out of three were still alive. Of all the 477 cases of laryngeal tuberculosis which passed through my service at Midhurst between 1911 and 1921 no less than 70.5 per cent. are now dead.

This darkening of the prognosis occurs in all stages of the disease (see Fig. 3). Of patients with-lesions in the lungs so limited that they were scheduled in Group I (of the Turban-Gerhardt classification) 82.6 were alive at a date when 50 per cent. of the patients with similar lung lesions, but with the addition of a deposit in the larynx, were dead. In Group II the mortality of laryngeal cases is more marked - two out of three cases are dead, while of those with a free larynx, two out of three were still alive. In Group IIIthat is, "adranced" cases-the difference is not so marked, for the mortality is so much higher with advanced pulmonary tuberculosis that the added danger of a laryngeal lesion is not so noticeable. Even in this group 42.3 per cent. of the patients were still alive amongst those with a free larynx, when only 22.7 per cent. survived, at the same date, of those in whom it was affected.

A glance at Fig. 3 will show that the mortality of laryngeal cases in Group $I$ is higher than it is amongst the pulmonary cases with more extensive lesions of Group II but with a normal larynx (that is, a mortality of 50 per cent. compared with 39.08 per cent.). In Group II this mortality is 66.3 per cent., compared with a rate of 57.4 per cent. in the larylix-free patients of Group III.

Put in another way, a Group I patient (that is, a "slight" case) with a laryngeal lesion has a worse prospect than a Group II case with a sound larynx. And a Group II case (that is, a " severe" case) with throat trouble has a gloomier expectation than if he had had a healthy larynx but lungs so invaded as to be classed in Group III (that is, an "advanced" case).

Differently expressed, the discovery of a laryngeal lesion at once moves a case down to a lower group.

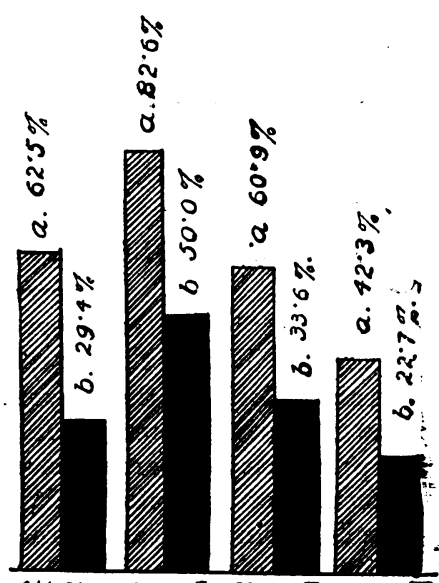

ALL CASES. GROUPI. GROUPII. GROUP III. a. LARYNX NORMAL. O. LARYNX DISEASED

Fig. 3.-Percentage surviving in 1922 (b) with larynx diseased from 1911 to 1921 .

In fact, in our tabulation of cases in King Edward Sanatorium there are no laryngeal cases in Group $I$. We think so badly of this complication that, even if only associated with quite early lung trouble, disease in the larynx moves such a patient down to Group II. Therefore laryngeal tuberculosis cannot be listed in any group which might be termed " slight" or " favourable." Its discovery at once labels a case as "severe," and authorizes a physician to warn his client that treatment will necessarily, even in the most hopeful cases, be long and arduous. In only too many instances (in 70.5 per cent. of my fairly favourable selection) it will be his duty to advise the friends that the prospect of a recovery is so slight that it may be unjustifiable to submit the sufferer to any trying, dangerous, or expensive treatment.

\section{Results of Treatment.}

From these rather gloomy conclusions let us turn to my record of 119 cures. To appraise them at a fair value I may be permitted to say that such a large total of well authenticated cases of healing in a larynx with tuberculosis has never before been published in this country. The satisfaction of quoting this record is enhanced when $I$ recall that in 1880 Morell Mackenzie wrote: "The prognosis of laryngeal phthisis is always extremely unfavourable and it is not certain that any cases ever recover" ; and that as late as 1908 a well known German authority stated that: "The cure of tuberculosis of the larynx is still to-day an exception." Sixteen years after these words were spoken I. am able to refer to 119 " exceptions"; many of them have been shown before sections of the Royal Society of Medicine; and some idea of the extent of lesion in which repair can be effected may be obtained by studying the illustrations shown on the screen. A complete repair of the larynx has been obtained in no less than 25 per cent. of patients with tuberculous laryngitis.

\section{Cures: How Obtained.}

I have no doubt that the principal factor in obtaining these arrests has been sanatorium regime and the prompt prescription of one or more of the threc chief methods of local treatment--namely, whispers, silence, and the galvanocautery. It certainly would be difficult to carry out the first two methods thoroughly except in a sanatorium. Their employment has always preceded the adoption of cautery application.

Fifty patients were cured-so far as local measures aro concerned-by the simple reduction of voice use entailed by 
whispers. This figure gave 14.8 per cent. as the proportion of cures in the 336 cases in which it was ordered. It may seem a small proportion, but it is low because all laryngeal patients are advised to limit voice use to whispers; many of them had no expectation of complete cure and were only put on "whispers" to avoid aggravation of the local trouble; others amongst them had, in addition, cautery treatment, and are therefore listed under that rubric.

Complete silence resulted in a cure in 23 instances, or in 34.3 per cent. of the cases in which it was ordered. The total of 23 cures out of 477 cases may seem small, but it was only carried out in 67 instances, for it was felt that such an ordeal should only be advised in promising cases. The number is also reduced by the subtraction of some who, in addition, had cautery treatment. The silence treatment was more successful with the women patients (41.6 per cent.) than with the men ( 25.8 per cent.). Women give a slightly higher percentage of cures, both with whisper's and silence. Their greater patience and endurance-or recovery power?-being most noteworthy in the ordeal of the silence cure.

The galvano-cautery yielded 46 cures. This method gives the highest proportion of satisfactory results in the 74 cases in which I tried it ( $=46$ per cent.), doubtless because the cases were carefully selected after being first watched, as a rule, for some months while under " whispers" or even silence. In one case the patient was fourteen months in the sanatorium before his larynx and general condition justified galvano-cautery treatment. ${ }^{3}$ This patient was able to earn his livelihood and remained well and active for years. He then died of pulmonary haemorrhage: the laryinx never relapsed. Another patient was a year under observation before the cautery could be used. She required fourteen treatments. It is seven years since the last; she is now free of bacilli and she earns her livelihood as a postmistress. These cases show that this method may be long and costly, fulfilling part of the saying that "the cure of tuberculosis requires a good stomach and a large purse !"

Results of Treatment by all Three Methods, of Silence, Whispers, and Galvano-cautery, in 477 Cases.

\begin{tabular}{ccc|c|c|c|c}
\hline & & Males. & Females. & Totals. & Per Cent. \\
\hline Arrested & $\ldots$ & $\ldots$ & 70 & 49 & 119 & 24.94 \\
Improved & $\ldots$ & $\ldots$ & 88 & 53 & 141 & 29.39 \\
Statu quo & $\ldots$ & $\ldots$ & 111 & 76 & 187 & 39.20 \\
Worse & $\ldots$ & $\ldots$ & 15 & 15 & 30 & 6.29 \\
\hline Total & $\ldots$ & $\ldots$ & 284 & 193 & 477 & \\
\hline
\end{tabular}

Durability of Cure.

After Silence.-Of 8 men cured by silence, 3 are alive at periods of one, two, and four years after discharge. The other 5 remained healed of their laryngeal lesions but have died from their pulmonary tubercle. Of 15 women, no less than 10 are alive and well after the lapse of two to ten years.

After Whispers.-Healing has been maintained in some cases for three, four, and even ten years. Fifteen out of 27 men, and 13 out of 23 women, are still alive and well.

After Galvano-cautery.-Of 46 cures, 28 are still alive, and in 6 of them the cured condition has persisted for ten years. As with the two preceding groups, the patients who are dead have succumbed to their pulmonary disease and, generally, without any laryngeal recurrence. Even of these I have been able to calculate that the average duration of life, after healing was complete, varied from two years and eight months in the men and to five years and two months in the women.

Benefit of a Healed Larynx.-During these years the patients were able to use their voices, and this voice use was not only a pleasure to them, but it remored the anxiety and depression which so many patients suffer from when tubercle attacks the larynx. The recovered voice also assisted them in their social duties and in gaining a livelihood.

Lasting Laryngeal Cures.-Thus of the 119 cases in which complete healing took place in the larynx, 69 are alive at periods varying from two to ten years afterwards. Fifty are dead, and they have died, as a rule, with a still cicatrized larynx. Their deaths, usually, were due to the extent or virulence of their pulmonary disease.

\section{Proportionate Progress of Pulmonary and Laryngeal Lesions.}

The above references to the durability of healing in the larynx, while the disease in the lungs progresses, are sufficient to show that tubercle does not necessarily progress pari passu in both situations. This latter view is still maintained, and, as it is not correct, it may occasionally mislead the physician.

Improvement very commonly does proceed along parallel lines, and, in the same way, a retrogression in one is often followed by progress of the disease in the other. For instance, a "flare-up" of temperature is generally followed by development of active signs in the chest and an increase of the disease in the larynx. But this is not constant. I have known of tubercle developing in the larynx just as the disease had become arrested in the lungs (and remaining so for twenty years) and the bacilli had disappeared from the sputum. On the other hand, I have frequently noted that the laryngeal disease had so far improved that the use of the cautery was indicated to complete the cicatrization, when $I$ have received the report that the pulmonary disease was progressing. Indeed, as recorded in the preceding paragraphs, spontaneous cure has taken place in the larynx in many cases, and has been maintained till the patient died of his pulmonary disease year's afterwards. But the reverse has never occurred-that is, I have never seen a larynx getting worse while the pulmonary disease has improved. It has occasionally, in such instances, been reported to me that the lung trouble was statu quo; but if the larynx did not mend the pulmonary disease inevitably, within a definite period, took on activity.

This is useful knowledge for the physician: a larynx may improve or get well, while the lung disease remains quiescent or gets worse; but if the disease in the larynx advances, the pulmonary disease cannot possibly become arrested, and soon makes progress. This again shows the value to the physician, from the point of prognosis, of periodic examination of the larynx.

\section{The Pessimistic Past of Tuberculous Laryngitis with} its more Optimistic Outlook.

The realization that of all my 477 cases, treated in a sanatorium during ten years, 70.5 per cent. are now dead is an arresting and a saddening thought. Nearly all of them were young people; few of them had induced their disease by vicious living; many of them had incurred it largely by excess of unselfishness or by a too ardont devotion to duty; and in no inconsiderable number it was directly due to their patriotic services in defending their country in the great war. This heavy toll demonstrates that tuberculosis in the larynx is always a serious complication of pulmonary disease. Physicians would be well advised to assure themselves of its presence or absence in any case of tuberculosis. If present, it adds considerably to the seriousness of the prognosis and to the prolongation of the care and time required for successful treatment, even in cases otherwise early and promising.

When the laryngeal lesion is extensive and active, the outlook is particularly serious. If the lesion is limited and becomes inactive, it may be arrested, although the prospect of life may not be great. From prolonged observations on nearly 500 sanatorium patients, a cure of the laryngeal lesion may be secured in one out of every four patients. These were, comparatively speaking, early cases. But a much higher proportion of cures could certainly be obtained 
if more cases of pulmonary tuberculosis were diagnosed while they are still Group I patients (that is, with only 4.8 per cent. showing laryngeal lesions) instead of Group III '(that is, with 31.5 per cent. with the larynx involved). More cures could be effected if every case of persistent huskiness or throat discomfort were earlier submitted to a skilled examination.

\section{Principles of Success in Trantment.}

It is manifest that a patient has a more sure hope of a quicker cure inside a well conducted sanatorium than he can expect otherwise. Even if he remains in a sanatorium only long enough to learn how to manage himself, this sojourn is highly beneficial. This is shown by the number of my cases which left Midhurst with the larynx still diseased but who kept up sanatorium principles and later on obtained complete and lasting cicatrization of their throat trouble.

The chief local requirement is voice rest, which can be so easily carried out in a sanatorium but is elsewhere so diffcult. Out of 119 cases which were cured, the healing was obtained without other local treatment than voice rest (whispers or silence) in no fewer than 73 instances. That such a simple treatment-though long and arduous for the patient-can be so effective should encourage perseverance with it when indicated.

Local surgical methods of cure have all been abandoned by me as useless and frequently harmful. My statistics show that a laryngeal lesion generally indicates an extensive lung lesion, or a very virulent infection, or lowered resistance. As things are at present, the majority of patients with laryngeal tuberculosis soon die (70.5 per cent.); they generally die of their lung disease. Topical surgical measures in the larynx are only apt to hasten this; their successful local results have never been frequent or enduring; and we have, in the galvano-cautery, a safer and more certain help. The galvano-cautery has, in my practice, superseded all other topical measures-curetting, injections, insufflations, application of lactic acid or other caustics. I have never seen a single case in which it has done harm, although in some it has been abandoned as useless. It effected a cure in 46 out of 74 cases in which it was tried (=62.1 per cent.). Of these 46 cures, 29 are alive and well; 12 of them have now maintained their cure for ten years. The galvano-cautery is the best local treatment we have at present. In suitable cases it has replaced all other methods.

\section{Conclusions.}

The majority of cases of tuberculosis of the larynx do not recover. It is necessary for the physician to recognize this, to try and determine which cases come within this category, and to act accordingly. But these 119 cures are witnesses of the more hopeful outlook we now have for a fair proportion of patients of whom an authority has said that, forty-five years ago, "all were doomed to die; the appearance of the disease in the larynx was the warrant of death."4

The pessimistic past has now a more optimistic outlook. As the Minister of Health said lately on a public occasion: "The fight against tuberculosis was a long one, but it was a winning one." 5 At the recent Congress on Tuberculosis in Lausanne (August, 1924) it was shown by Sir Robert Philip that this fight is being won, not simply by the population becoming immunized or by such general advances as improved national health and hygiene, but by the measures of direct attack originated and inspired by our profession. ${ }^{6}$

\section{RIFERENCES}

1 StClair Thomson: Tuberculosis of the Larynx: Ten Years' Experience in a Sanatorium. Medical Research Council. His Majesty's Stationery Office. 1924. Price 2s. 6d.

${ }^{2}$ StClair Thomson: The History of Rhino-Laryngology in Great Britain Journ. of Laryngol., 1913, vol. xxviii, No. 8, p. 394.

3 proceedings of the Section of Laryngology, Royal Society of Medicine, $\mathrm{x}, 1917,16$.

J. Nolan Mackenzie: Journ. of Laryngol., 1916, 31, 411

s British Medicil Journ.iL, 1924, July 12th, p. 61

- Bdinburgh Med. Journ., September, 1924.

\section{CERVICAL RIBS IN CHILDREN.}

BY

A. H. SOUTHAM, M.D., M.Ch.Oxon., F.R.C.S.Exg., ASSISTANT SURGEON, ROYAL MAYCHESTER CHILDREN'S HOSPITAL ; ASSISTANT SURGICAL OFFICER, MANCHESTER ROYAL IAFIRMARY; VISITING SURGEON, STEPEING HILL HOSPITAL, STOCKPORT;

AND

W. J. S. BYTHELL, O.B.E., B.A.CantaB., M.D.Vict., HON. RADIOLOGIST TO THE ROYAL MANCHESTER CHILDREN'S HOSPITAL AND THE SALFORD ROYAL HOSPTTAL; CONSULTING RADIOLOGIST TO THE MINISTRY OF PENSIONS.

Ever since Sir William Thorburn ${ }^{1}$ in 1905 showed that certain symptoms in the upper limb were associated with the presence of cervical ribs, an increasing number of reports upon this condition have appeared in medical literature. Supernumerary ribs have been recorded in both sexes and at all ages. Thorburn states that the earliest age he has met. with them was the serenteenth year. Sir William Turner ${ }^{2}$ refers to a case described by Rosenmüller in an embryo of six months, and Stiles $^{3}$ has also recorded a case in a female infant of 18 months. Nevertheless, comparatively little attention has been directed to the presence of cervical ribs as a possible cause of symptoms in children, and this paucity of data is all the more striking when one considers the increasing use of radiography at the present time. It is undoubtedly true that in the majority of cases the symptoms produced by cervical ribs do not appear until adult life is reached, and that in young children attention is perhaps only drawn to their presence by a prominence in the neck or by the accidental diseovery of the condition in a radiograph of the neck.

The four cases of cervical ribs in children described in this paper have recently come under our observation and have led us to make further investigation into the frequency of their occurrence. The result has been to convince us that this condition has not received the consideration which it deserves.

The first of the four cases occurred in a girl 4 years of age, and although the ribs were causing no pressure symptoms, the child was brought to the Roval Manchester Children's Hospital early this year on account of two hard masses above the clavicle. The swellings were very prominent and extended from the spine to the first dorsal ribs. Radiological examination showed that bilateral cervical ribs were present. In the absence of any symptoms no treatment has been deemed necessary up to the present time.

In the second case, however, the pressure effects were so definite that operative treatment was clearly indicated. The case is worthy of detailed record, as it is unusual to find such typical symptoms at so early an age.

M. G., a girl aged 12 years, was brought to the Manchester Northern Hospital in June, 1923, complaining of neuralgic pain in the left forearm and hand, and a constant irritating cough. She was first seen by Dr. Mather, who was unable to find any clinical signs in the chest to account for the cough, but discorered a swelling in the left side of the neck. He referred the child to one of us for further investigation and treatment as being a case of suspected cervical rib. Examination revealed a hard bony tumour above the left clavicle, with some atrophy of the intrinsic muscles of the left hand. Pain was complained of along the ulnar border of the forearm and hand, but no circulatory or troplic disturbances were present. A radiogram demonstrated the presence of a large cervical rib on the left side arising from the seventh cervical vertebra. Operation for its removal was advised, and 1/1is we carried out shortly afterwards. A flap was made along the upper border of the clavicle and behind the sterno-mastoid muscle, the brachial plexus being then exposed. The plexus was seen crossing the cervical rib, the inner trunk lying directly on the bone. The rib was cleared in front and disarticulated through its juncture with the first dorsal rib, finally being divided behind with bonecutting pliers as far back as possible. During its removal the pleura was damaged, but no trouble resulted from its injury. 